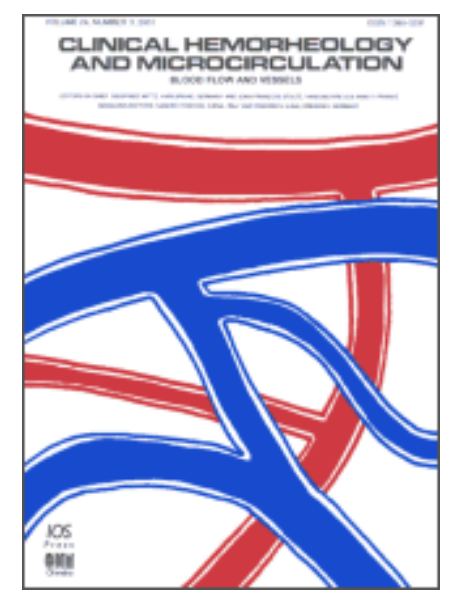

\title{
Cell-specific regulation of acetylcholinesterase expression under inflammatory conditions
}

\begin{tabular}{|c|c|}
\hline Journal & Clinical Hemorheology and Microcirculation \\
\hline Publisher & IOS Press \\
\hline & 1386-0291 (Print) \\
\hline ISSIN & 1875-8622 (Online) \\
\hline Subject & $\begin{array}{l}\text { Medicine, Biochemistry and Biophysics and } \\
\text { Hematology }\end{array}$ \\
\hline Issue & Volume 51, Number 2 / 2012 \\
\hline Pages & $129-137$ \\
\hline DOI & 10.3233/CH-2011-1520 \\
\hline $\begin{array}{l}\text { Subject } \\
\text { Group }\end{array}$ & Medicine and Health \\
\hline Online Date & $\begin{array}{l}\text { Tuesday, January 03, } 2012 \\
\text { Serviços } 9^{\circ} \text {. Texto Integral @ b-on }\end{array}$ \\
\hline
\end{tabular}

\section{Authors}

P. de Oliveira ${ }^{1}$, A.Q. Gomes ${ }^{2}$, T.R. Pacheco ${ }^{1}$, V. Vitorino de Almeida ${ }^{1}$, C. Saldanha ${ }^{1}$, A. Calado $^{1}$

${ }^{1}$ Instituto de Medicina Molecular, Faculdade de Medicina da Universidade de Lisboa, Lisboa, Portugal

${ }^{2}$ Escola Superior de Tecnologia da Saúde de Lisboa, Lisboa, Portugal 


\begin{abstract}
Acetylcholine (ACh) has been shown to exert an anti-inflammatory function by downmodulating the expression of pro-inflammatory cytokines. Its availability can be regulated at different levels, namely at its synthesis and degradation steps. Accordingly, the expression of acetylcholinesterase (AChE), the enzyme responsible for ACh hydrolysis, has been observed to be modulated in inflammation. To further address the mechanisms underlying this effect, we aimed here at characterizing AChE expression in distinct cellular types pivotal to the inflammatory response. This study was performed in the human acute leukaemia monocytyc cell line, THP-1, in human monocyte-derived primary macrophages and in human umbilical cord vein endothelial cells (HUVEC). In order to subject these cells to inflammatory conditions, THP-1 and macrophage were treated with lipopolysaccharide (LPS) from E.coli and HUVEC were stimulated with the tumour necrosis factor $\alpha$ (TNF- $\alpha$ ). Our results showed that although AChE expression was generally up-regulated at the mRNA level under inflammatory conditions, distinct $\mathrm{AChE}$ protein expression profiles were surprisingly observed among the distinct cellular types studied. Altogether, these results argue for the existence of cell specific mechanisms that regulate the expression of acetylcholinesterase in inflammation.
\end{abstract}

Keywords

Acetylcholinesterase, inflammation, gene expression 